\begin{tabular}{|c|l|}
\hline Title & Enrichment in axial direction of aqueous foam in continuous foam separation \\
\hline Author(s) & Maruyama, Hideo; Suzuki, A kira; Seki, Hideshi; Inoue, Norio \\
\hline Citation & $\begin{array}{l}\text { Biochemical Engineering Journal, 30/3), 253-259 } \\
\text { https://doi.org/L0.1016/.bej.2006.05.004 }\end{array}$ \\
\hline Issue Date & 2006-06-25 \\
\hline Doc URL & http://hdl.handle.net/2115/14403 \\
\hline Type & article (author version) \\
\hline File Information & maruyama_etal_06_BEJ_accepted.pdf \\
\hline
\end{tabular}

Instructions for use 


\title{
Enrichment in Axial Direction of Aqueous Foam in Continuous
}

\section{Foam Separation}

\author{
Hideo Maruyama , Akira Suzuki, Hideshi Seki, Norio Inoue
}

Division of Marine Biosciences, Graduate School of Fisheries Sciences, Hokkaido University, Minato 3-1-1 Hakodate 041-8611, JAPAN

TEL:+81-138-408813; FAX:+81-138-408811; E-mail:

maruyama@elsie.fish.hokudai.ac.jp

* Corresponding author

E-mail address: maruyama@elsie.fish.hokudai.ac.jp (H. Maruyama) 


\begin{abstract}
Estimation of overhead production enrichment in continuous foam separation was conducted with a surfactant: sodium $n$-dodecylbenzenesulfonate (SDBS), and soluble proteins: ovalbumin (OA) and hemoglobin (HB). Axial profiles of the volumetric flow rate and the concentration of the collapsed foam liquid within the column were measured, and the enrichment ratio and the liquid holdup in axial direction were determined experimentally. The proposed model was fitted to the experimental results obtained with various experimental conditions (superficial gas velocity, feed concentration, and $\mathrm{pH}$ ) and was in reasonable agreement with the experimental data by using the least square regression. The present model makes it possible to estimate the foamate concentration at a desired foam height.
\end{abstract}

Keywords: Adsorption; Bioseparations; Bubble Columns; Separation; Foam separation; Protein 


\section{Introduction}

The foam separation technique has been widely used in ore flotation [1], waste water treatment [2], and food and biochemical industries [3-7].Especially this technique is useful to enrich objective surface-active substances from dilute aqueous solution. The enrichment process is mainly dominated by (i) adsorption of objective substances onto bubble surface within bubble dispersed bed and (ii) drainage within foam bed.

It has been well known empirically that concentration of foamate (collapsed foam liquid) increased exponentially in the axial direction within the foam because of liquid film thinning and drainage of liquid in foam due to gravitational acceleration and plateau border suction. This fact suggests that the concentration of the liquid in the foam will be changed with the overflowing and the sampling position in the axial direction of the column. It is important to estimate the degree of the enrichment at each axial positions for operating this technique.

Many investigators proposed the model for liquid drainage in foam. Hartland and Barber [8] proposed a model for cellular foams in batch foaming system by considering the liquid holdup in the cellular foam proposed the physical model. Kumar and Desai [11-13] have proposed a model which has been considered thinning of the liquid film, the plateau border suction and the axial/lateral directions of liquid flow in foam. Narsimhan and Ruckenstein [14,15] developed the drainage model based on the model proposed by Desai and Kumar [11].Other mathematical and physical models on liquid drainage in foam have been reported [16-19]. These models have physical and mathematical rigidity, however, these make it difficult to use with ease practically because of mathematical complexity 
and many parameters.

In this study, a simple model for estimation of the enrichment within foam bed in axial direction was proposed with two parameter. Continuous foam separation experiments were conducted with sodium $n$-dodecylbenzenesulfonate (SDBS), ovalbumin (OA) and hemoglobin (HB). The proposed model will be verified with the experimental results. 


\section{Description of enrichment model}

\subsection{Enrichment ratio in foam bed}

In continuous foam separation, the concentration, $C_{\mathrm{f}}$, of the collapsed foam liquid is expressed as the following equation from the mass balance:

$$
C_{\mathrm{f}}=\frac{S_{\mathrm{f}} X+\varepsilon C_{\mathrm{b}}}{\varepsilon},
$$

where, $\varepsilon$ and $S_{\mathrm{f}}$ are the liquid holdup and surface area of bubbles per unit volume in the foam bed at height $H$ from the liquid-foam interface, respectively. $C_{\mathrm{b}}$ is the concentration of the bulk liquid in the column. $X$ is the adsorption density on bubble surface. Enrichment ratio is defined as:

$$
E \equiv \frac{C_{\mathrm{f}}}{C_{\mathrm{b}}} .
$$

Approximately, the liquid holdup can be expressed as:

$\varepsilon=S_{\mathrm{f}} \delta$

$\delta$ is the thickness of liquid film. Moreover, $X$ is expressed by Langmuir's type isotherm [20-22]: 


$$
X=\frac{K C_{\mathrm{b}}}{1+K C_{\mathrm{b}}},
$$

where, $K$ and $\gamma$ represent the equilibrium adsorption constant and the saturated surface density, respectively. The following relationship is derived from Eqs. (1) (4):

$$
S_{\mathrm{f}}=\frac{\varepsilon(E-1)\left(1+K C_{\mathrm{b}}\right)}{\gamma K} .
$$

Then, if variation in $S_{\mathrm{f}}$ in foam height is small, that is, assuming that the surface area, $S_{\mathrm{fo}}$, of bubbles at liquid-foam interface within the column is mostly equal to $S_{\mathrm{f}}[22,23]$, the following relationship is also derived from Eq. (5):

$$
E-1=\frac{S_{\mathrm{f} 0} \gamma K}{\varepsilon\left(1+K C_{\mathrm{b}}\right)} .
$$

Therefore, if variation in $\varepsilon$ in axial direction can be known, variation in $E$ will be determined.

\subsection{Liquid holdup in foam bed}

Assuming that the decreasing rate of the liquid holdup is proportional to the present liquid holdup, the next relationship is obtained as: 
$\frac{d \varepsilon}{d t}=-\alpha \varepsilon$,

where $\alpha$ is decreasing rate coefficient. Relationship between the superficial gas velocity, $u_{\mathrm{g}}$, and rising velocity, $v$, of gas is expressed as:

$u_{\mathrm{g}}=v(1-\varepsilon)$

In foam bed, gas (bubbles) accompany with liquid in foam, therefore, rising velocity of the liquid in foam should be equal to $v$. In the present conditions, the liquid holdup is sufficiently smaller than 1 , thus, the rising velocity of the foam within the column will seem to be equal to the superficial gas velocity. Therefore, displacement of the foam for $d t$ is expressed as:

$d H=v d t=u_{\mathrm{g}} d t$

From Eqs. (7) and (9), the next equation is obtained.

$$
\left(\frac{1}{\varepsilon}\right) d \varepsilon=-\left(\frac{\alpha}{u_{\mathrm{g}}}\right) d H .
$$

By solving Eq. (10) with an initial condition $\left(\varepsilon=\varepsilon_{0}\right.$ at $H=0$ ),

$$
\varepsilon=\varepsilon_{0} \exp \left\{-\left(\alpha / u_{\mathrm{g}}\right) H\right\} .
$$


$\varepsilon_{0}$ is the liquid holdup at the liquid - foam interface $(H=0)$.

\subsection{Determination of parameter}

Finally, the following equation is obtained from Eqs. (6) and (11):

$$
\ln (E-1)=\ln \frac{S_{\mathrm{f} 0} \gamma K}{\varepsilon_{0}\left(1+K C_{\mathrm{b}}\right)}+\frac{\alpha}{u_{\mathrm{g}}} H .
$$

Plot of $\ln (E-1)$ versus $H$ will give a straight line. By comparing the experimental values with Eq. (11), $\alpha$ and $\varepsilon_{0}$ will be determined, and $S_{\mathrm{f} 0}$ will be also determined by intercept of Eq. (12). 


\section{Experiments}

\subsection{Materials}

Ovalbumin (egg white) (OA) was purchased from Eastman Kodak Company or Difco Laboratories. Hemoglobin from bovines (HB) and sodium n-dodecylbenzenesulfonate (SDBS) were purchased from Wako Pure Chemical Industries, Ltd. (Japan). These were used without further purification. The ion strength and $\mathrm{pH}$ of protein solutions were adjusted with $\mathrm{NaCl}$ at $5 \times 10^{-3} \mathrm{M}$ and with aqueous $\mathrm{HCl}$ or $\mathrm{NaOH}$ to several desired values.

\subsection{Experimental setup}

A foam column used in this study was almost the same apparatus as described in the previous studies [22-24]. The column was constructed of a transparent acrylic resin tube of $4.4 \mathrm{~cm}$ inside diameter and $95 \mathrm{~cm}$ in height. A sintered glass filter with average pore size from 10 to $15 \mu \mathrm{m}$ was installed as a gas distributor at the bottom of the column. Nitrogen gas was supplied to the column through the distributor as bubbles. In the experiments, a foam collector was equipped at the top of the column to entrap foam generated from the liquid surface. Pressure taps for measuring gas holdup in the column were along the wall installed at intervals of $25 \mathrm{~cm}$.

\subsection{Experimental procedures}


The procedures are also almost the same as those described in our previous paper [22]. The solutions were charged into the column from a feed tap by a quantitative pump. The volumetric flow rate of feed liquid was $0.5 \mathrm{~cm}^{3} / \mathrm{s}$. After confirming a steady state in the bulk liquid, sampling of the foam liquid for measuring the volumetric flow rates and the concentrations was started. The concentrations of SDBS and proteins (OA or $\mathrm{HB}$ ) were measured spectrophotometrically (JASCO U-best30) at $220 \mathrm{~nm}$ and by the Lowry method [25], respectively. The $\mathrm{pH}$ of the bulk liquid in the column was measured with a pH meter (ORION Model SA 520). The gas holdup was determined from the difference in static pressure between the clear and aerated liquids using a differential pressure transducer. Voltage signals were recorded by a personal computer (NEC PC-9801VM) via A/D converter (CONTEC). 


\section{Results and Discussion}

\subsection{Surface area of bubbles in foam bed}

The $\varepsilon$ was determined from the next relationship:

$$
\varepsilon=\frac{W_{\mathrm{f}}}{W_{\mathrm{f}}+A u_{\mathrm{g}}} .
$$

$W_{\mathrm{f}}$ and $A$ are the volumetric flow rate of the liquid in foam within the column and the cross-sectional area of the column, respectively. Typical results of $S_{\mathrm{f}}$ are shown in Fig. 1. Plotting points (all keys) in Fig. 1 were calculated by Eq. (5). $K$ and $\gamma$ used in the calculation are summarized in Table 1 . The values of $K$ and $\gamma$ for $\mathrm{OA}$ and HB were determined by continuous foam separation experiments [22]. The value of these for SDBS was also determined by the same method in the present study. The value of $\gamma$ for SDBS was mostly close to the values in literature $[26,27]$. The scatters of data for OA and HB should be caused by the measurement error of $W_{\mathrm{f}}$. In case of $\mathrm{HB}$, although remarkable coalescence of bubbles within the foam was not observed visually, however, the foam of HB seemed to be more dry and cellular foam rather than the foam of OA. Therefore, more high concentration region had to be employed in case of HB. In comparison with values of $\gamma$ for OA and $\mathrm{HB}$ at i.e.p., $\gamma$ for OA is 1.5-fold larger than that for HB (Table 1). This may affect that OA foam seems to be more stable than HB foam in Fig. 1. As shown in the figure, $S_{\mathrm{f}}$ was not varied widely in the axial direction. Thus, $S_{\mathrm{f}}$ seemed to be constant in the present experimental conditions for SDBS, OA and HB. 


\subsection{Verification of the present model}

Typical experimental results of the liquid holdup, $\varepsilon$, are shown in Fig. 2. $\varepsilon$ decreased abruptly and exponentially near the liquid-foam interface $(H=0)$. This tendency was almost the same as observations reported in literature [10-19]. The slope of $\varepsilon$ increased with decreasing $C_{\mathrm{b}}$. The solid lines in the figure were obtained by fitting of the data to Eq. (11). the calculated values agreed well with the experimental ones by giving adequate values for $\alpha$ and $\varepsilon_{0}$. Fig. 3 shows fitting of the data to Eq. (12). Solid lines in this figure are the calculated values by Eq. (12). Good agreement between the experimental values and the calculated ones was recognized. These results would support the validity of the present model.

\subsection{Parameters estimated from the present model}

Fig. 4 shows change in $\alpha$ in function of $C_{b}$. $\alpha$ should reflect a degree of drainage of liquid through the liquid film. $\alpha$ tended to decrease with increasing $C_{\mathrm{b}}$. In comparison with value of $\alpha$ for SDBS (Fig. 4(a)) and proteins (Fig. 4(b); OA and $\mathrm{HB}$ ), protein foam seemed to be stable and wet comparatively in lower bulk concentration region. In Fig. 4(b), influence of $\mathrm{pH}$ was slightly observed at $\mathrm{pH} 4.6$ for OA (open triangle). and at $\mathrm{pH} 6.0$ for $\mathrm{HB}$ (open circle and open diamond). a values for these are lower than that for the other $\mathrm{pH}$ for $\mathrm{OA}$ and $\mathrm{HB}$, respectively. At the $\mathrm{pH}$ (4.6 for $\mathrm{OA}$ and 6.0 for $\mathrm{HB}$ ), the value of $K$ is largest than that at the other $\mathrm{pH}$. 
In the present experimental conditions, the surface tension value were $6.5 \times 10^{-2}$ - $4.9 \times 10^{-2}$ and $6.5 \times 10^{-2}-4.4 \times 10^{-2} \mathrm{~N} / \mathrm{m}$ for proteins and SDBS, respectively, which were not varied widely. The values of liquid viscosity also hardly varied $\left(0.9-1.1 \times 10^{-3} \mathrm{~kg} /(\mathrm{m} \mathrm{s})\right)$. Slightly change in surface tension and liquid viscosity would greatly affect $\alpha$. At this point, we cannot exactly explain what physical properties of the liquids affect the foam stability from the present experimental data and our analysis. Some literature have pointed out that surface viscosity was one of important factor concerning foam stability and liquid drainage within foam [11, 12, 28, 29], although we could not measure it.

The foam at the liquid-foam interface was considered to be consisted by accumulation of bubbles rising through the column and liquid films around bubbles. Thus, the liquid holdup, $\varepsilon_{0}$, at liquid-foam interface can be expressed as:

$$
\varepsilon_{0}=1-\left(1+\frac{\delta_{0}}{r_{\mathrm{b}}}\right)^{-3}
$$

Where, $\delta_{0}$ and $r_{\mathrm{b}}$ represent the thickness of the liquid film around one bubble and the radius of the bubble accumulated at the liquid-foam interface within the column, respectively. The $r_{\mathrm{b}}$ was determined by the following equation, because $r_{\mathrm{b}}$ was considered to equal to the radius of bubbles rising through the bulk liquid within the column [22-24]: 


$$
r_{\mathrm{b}}=\frac{u_{\mathrm{g}}}{2 \varepsilon_{\mathrm{g}}\left(1-\varepsilon_{\mathrm{g}}\right)^{4.65}\left[\left(\frac{4}{225}\right) \cdot \frac{\left(\rho_{\mathrm{l}}-\rho_{\mathrm{g}}\right)^{2} g^{2}}{\mu_{\mathrm{l}} \rho_{\mathrm{l}}}\right]^{\frac{1}{3}}},
$$

where $\varepsilon_{\mathrm{g}}, \mathrm{g}, \rho_{\mathrm{l}}, \rho_{\mathrm{g}}$, and $\mu_{\mathrm{l}}$ represent the gas holdup in the bubble dispersion phase, the gravitational acceleration, the densities of liquid and gas, and the viscosity of the liquid, respectively. Fig. 5 shows the relationship between $\varepsilon_{0}$ and $r_{\mathrm{b}}$. Solid lines in the figure were calculated from Eq. (14). The $\delta_{0}$ for both SDBS and proteins (OA and $\mathrm{HB}$ ) were determined by a least squares method, in this case, values of $\delta_{0}$ for both SDBS and proteins were 8 and $20 \mu \mathrm{m}$, respectively. $\varepsilon_{0}$ would be explained by the relationship of Eq. (14), although some scatters were observed. Influence of $\mathrm{pH}$ on $\varepsilon_{0}$ and $r_{\mathrm{b}}$ for both $\mathrm{OA}$ and $\mathrm{HB}$ was not observed in Fig. 5 because of some scatters. This suggests that $\varepsilon_{0}$ was mostly affected by bubble size. The most estimated $r_{\mathrm{b}}$ for proteins concentrated in the range of from about 0.05 to $0.09 \mathrm{~cm}$ and the data scattered appreciably. This reason cannot be clarified for the present. However, Eq. (14) can represent the tendency of change in $\varepsilon_{0}$ adequately for the present system. 


\section{Conclusions}

The axial enrichment ratio profile in foam bed for continuous foam separation column were studied and can be expressed by the present model. Good agreement between the experimental results of the axial enrichment profiles and the calculated values was obtained for both proteins (ovalbumin (OA) and hemoglobin (HB)) and sodium n-dodecylbenzenesulfonate (SDBS) by determining the two model parameters using least squares method. $\alpha$ was mostly influenced by the concentration of the bulk liquid, that is, slightly change in surface tension and liquid viscosity would greatly affect $\alpha$. The liquid holdup, $\varepsilon_{0}$, at the liquid-foam interface within the column was expressed in function of the bubble radius, $r_{\mathrm{b}}$, and the thickness, $\delta_{0}$, of the liquid film, and $\delta_{0}$ was estimated 8 and $20 \mu \mathrm{m}$ for SDBS and proteins, respectively. The present model can relatively ease to estimate the enrichment in axial direction of foam height in continuous foam separation. Further development and study are required for application of the present model to the other substances or experimental conditions to confirm the verification of the present model. 


\section{Notation}

$\begin{array}{llr}A & =\text { a cross-sectional area of bubble column } & {\left[\mathrm{m}^{2}\right]} \\ C_{\mathrm{b}} & =\text { equilibrium concentration of the bulk liquid in bubble column } & {\left[\mathrm{kg} / \mathrm{m}^{3}\right]} \\ C_{\mathrm{f}} & \text { = the concentration of the liquid in foam within the column } & {\left[\mathrm{kg} / \mathrm{m}^{3}\right]} \\ r_{\mathrm{b}} & =\text { bubble radius } & {[\mathrm{m}]} \\ E & =\text { enrichment ratio defined by Eq. (2) } & {[-]} \\ H & \text { = foam height } & {[\mathrm{m}]} \\ g & =\text { gravitational acceleration } & {\left[\mathrm{m} / \mathrm{s}^{2}\right]} \\ K & =\text { equilibrium adsorption constant } & {\left[\mathrm{m}^{3} / \mathrm{kg}\right]} \\ S_{\mathrm{f}} & =\text { bubble surface area in foam per unit volume } & {\left[\mathrm{m}^{2} / \mathrm{m}^{3}\right]} \\ S_{\mathrm{f} 0} & \text { = bubble surface area at liquid-foam interface per unit volume } & {\left[\mathrm{m}^{2} / \mathrm{m}^{3}\right]} \\ u_{\mathrm{g}} & =\text { superficial gas velocity } & {[\mathrm{m} / \mathrm{s}]} \\ v & =\text { rising velocity of bubble in foam bed } & {[\mathrm{m} / \mathrm{s}]} \\ W_{\mathrm{f}} & \text { = the volumetric flow rate of the liquid in foam } & {\left[\mathrm{m}^{3} / \mathrm{s}\right]} \\ X & \text { = adsorption density } & {\left[\mathrm{kg} / \mathrm{m}^{2}\right]}\end{array}$

\section{Greek symbols}

$\alpha \quad=$ decreasing rate coefficient

$\delta \quad=$ thickness of liquid film

$\varepsilon \quad=$ liquid holdup in foam bed

$\varepsilon_{0} \quad=$ liquid holdup at liquid-foam interface

$\varepsilon_{\mathrm{g}} \quad=$ gas holdup in bubble dispersed phase

$\gamma=$ saturated adsorption density

$\mu_{1} \quad=$ liquid viscosity 
$\rho_{\mathrm{g}} \quad=$ gas density

$\left[\mathrm{kg} / \mathrm{m}^{3}\right]$

$\rho_{\mathrm{I}}=$ liquid density

$\left[\mathrm{kg} / \mathrm{m}^{3}\right]$ 


\section{References}

[1] D.W. Fuerstenau, T.W. Healy, Adsorptive Bubble Separation Techniques, Academic Press, New York, 1972.

[2] D. Jenkins, J. Scherfig, D.W. Eckhoff, Adsorptive Bubble Separation Techniques. Academic Press, New York, 1972.

[3] P. Bhattacharya, S.K. Ghosal, K. Sen, Effect of physicochemical parameters on the separation of proteins from human placental extract using a continuous foam fractionating column, Sep. Sci. Technol. 26 (1991) 1279-1293.

[4] L.G. Brown, G. Narsimhan, P.C. Wankat, Foam fractionation of globular proteins, Biotechnol. Bioeng. 36(9) (1990) 947-959.

[5] S.B. Mohan, L. Smith, W. Kemp, A. Lyddiatt, An immunochemical analysis of beer foam, J. Inst. Brew. 98(3) (1992) 187-192.

[6] G.A. Montero, T.F. Kirchner, R.D. Tanner, Bubble and foam concentration of cellulase, Appl. Biochem. Biotechnol. 39/40 (1993) 467-475.

[7] P. Sarkar, P. Bhattacharya, R.N. Mukerjea, M. Mukerjea, Isolation and purification of protease from human placenta by foam fractionation, Biotechnol. Bioeng. 29(8) (1987) 934-940.

[8] V. Burapatana, A. Prokop, R.D. Tanner, Enhancing cellulase foam fractionation with addition of surfactant, Appl. Biochem. Biotechnol. 121-124 (2005) 541-552.

[9] V. Burapatana, E.A. Booth, A. Prokop, R.D. Tanner, Effect of buffer and $\mathrm{pH}$ on detergent-assisted foam fractionation of cellulase, Ind. Eng. Chem. Res. 44(14) (2005) 4968-4972. 
[10] S. Hartland, A.D. Barber, A model for cellular foam, Trans. Inst. Chem. Eng. 52(1) (1974) 43-52.

[11] D. Desai, R. Kumar, Flow through a plateau border of cellular foam, Chem. Eng. Sci. 37(9) (1982) 1361-1370.

[12] D. Desai, R. Kumar, Liquid holdup in semi-batch cellular foams, Chem. Eng. Sci. 38(9) (1983) 1525-1534.

[13] D. Desai, R. Kumar, Liquid overflow from vertical co-current foam columns, Chem. Eng. Sci. 39(11), (1984) 1559-1570.

[14] G. Narsimhan, E. Ruckenstein, Hydrodynamics, enrichment, and collapse in foams, Langmuir 2(2) (1986a) 230-238.

[15] G. Narsimhan, E. Ruckenstein, Effect of bubble size distribution on the enrichment and collapse in foams, Langmuir 2(4) (1986b) 494-508.

[16] G. Verbist, D. Weaire, A.M. Kraynik, The foam drainage equation, J. Phys. Condens. Matter 8(21), (1996) 3715-3731.

[17] S.A. Koehler, H.A. Stone, M.P. Brenner, J. Egger, Dynamics of foam drainage, Physical Review E 58(2-B) (1998) 2097-2106.

[18] M. Duraud, G. Martinoty, D. Langevin, Liquid flow through aqueous foams: from the plateau border-dominated regime to the node-dominated regime, Physical Review E 60(6) (1999) R6307-R6308.

[19] S.A. Koehler, S. Hilgenfeldt, H.A. Stone, Liquid flow through aqueous foams: the node-dominated foam drainage equation. Physical Review Letters 82(21) (1999) 4232-4235.

[20] A. Suzuki, H. Maruyama, H. Seki, T. Hayashi, Application of nonfoaming bubble separation to enrichment of dilute dye solution, J. Chem. Eng. Jpn. 28(1) (1995) 115-117. 
[21] A. Suzuki, H. Maruyama, H. Seki, Adsorption behavior of organic substances onto bubble surface in nonfoaming bubble separation, J. Chem. Eng. Jpn. 29(5) (1996) 794-798.

[22] H. Maruyama, A. Suzuki, H. Seki, Adsorption of water-soluble proteins onto bubbles in continuous foam separation, J. Colloid Interface Sci. 224(1), (2000) 76-83.

[23] A. Suzuki, H. Maruyama, Influence of liquid properties and operating variables on enrichment ratio in nonfoaming and foaming adsorptive bubble separation techniques, J. Colloid Interface Sci. 238(1) (2001) 54-61.

[24] A. Suzuki, K. Yasuhara, H. Seki, H. Maruyama, Selective foam separation of binary protein solution by SDS complexation method, J. Colloid Interface Sci. 253(2) (2002) 402-408.

[25] O.H. Lowry, N.J. Rowebrough, A.L. Farr, R.J. Randall, Protein measurement with the folin phenol reagent, J. Biol. Chem. 193(1) (1951) 265-275.

[26] E. Rubin, J. Jorne, Foam separation of solutions containing two ionic surface-active solutes, Ind. Eng. Chem. Fundam. 8(3) (1969) 474-482.

[27] T. Shirotsuka, M. Ishiwata, Studies on bubble fractionation - adsorption rate and elimination of D.B.S.-, Kagaku Kougaku 37(4) (1973) 397-402 (in Japanese).

[28] I.L. Jashnani, R. Lemlich, Foam drainage, surface viscosity, and bubble size bias, J. Colloid Interface Sci. 46(1) (1974) 13-16.

[29] K. Fujita, T. Miyahara, Stability of cellular foam formed from anionic and cationic surfactant aqueous solution, Kagaku Kougaku Ronbunshu 32(2) (2006) 103-114 (in Japanese). 


\section{Captions of Figures and Tables}

Fig. 1. Change in surface area, $S_{\mathrm{f}}$, of bubbles in the axial direction of foam bed. Experimental conditions are (a) SDBS, $u_{\mathrm{g}}=3.97 \times 10^{-2} \mathrm{~cm} / \mathrm{s}$, (b) SDBS, $u_{\mathrm{g}}=$ $6.66 \times 10^{-2} \mathrm{~cm} / \mathrm{s}$, (c) ovalbumin, $\mathrm{pH} 4.6, u_{\mathrm{g}}=5.37 \times 10^{-2} \mathrm{~cm} / \mathrm{s}$, and (d) hemoglobin, $\mathrm{pH} 6.8, u_{\mathrm{g}}=5.37 \times 10^{-2} \mathrm{~cm} / \mathrm{s}$, respectively.

Fig. 2. Axial distribution of liquid holdup, $\varepsilon$, for SDBS ((a) and (b)), ovalbumin (c) and hemoglobin (d) in foam within continuous foam separation column. Symbols and experimental conditions are same as Fig. 1. Solid lines were calculated from Eq. (11).

Fig. 3. Comparison of the experimental values of $\ln (E-1)$ and the calculated ones for SDBS ((a) and (b)), ovalbumin (c) and hemoglobin (d) in foam within continuous foam separation column. Symbols and experimental conditions are same as Fig. 1. Solid lines were the results of fitting of the data to Eq. (12).

Fig. 4. Variation in $\alpha$ estimated from Eq. (11) for SDBS, ovalbumin (OA) and hemoglobin (HB).

Fig. 5. Relationship between $\varepsilon_{0}$ estimated from Eq. (11) and bubble radius, $r_{\mathrm{b}}$, determined by Eq. (15) for SDBS, ovalbumin (OA) and hemoglobin (HB).

Table 1. Adsorption parameters for proteins and SDBS 

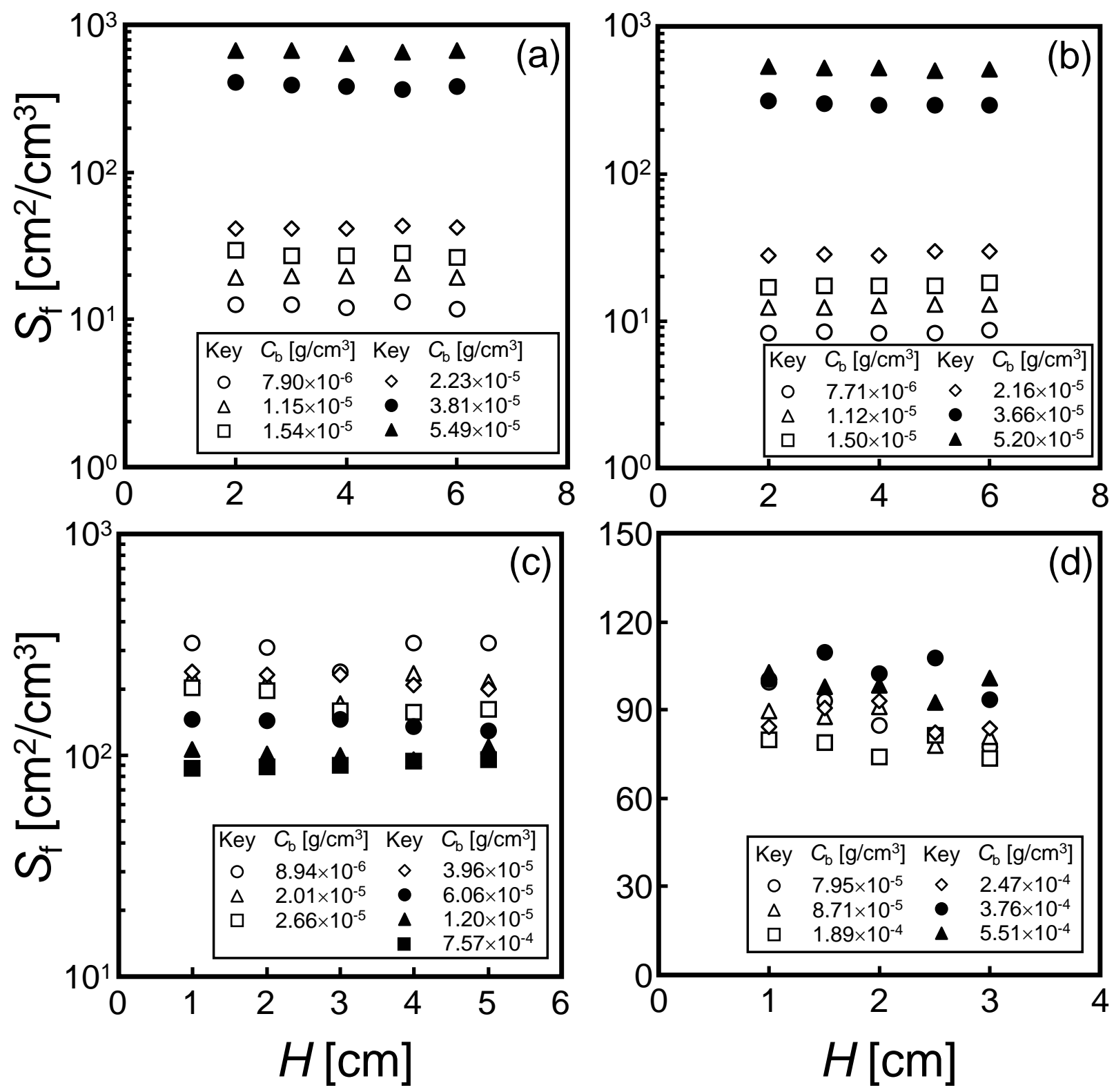

Fig. 1. Change in surface area, $S_{\mathrm{f}}$, of bubbles in the axial direction of foam bed. Experimental conditions are (a) SDBS, $u_{\mathrm{g}}=3.97 \times 10^{-2} \mathrm{~cm} / \mathrm{s}$, (b) SDBS, $u_{\mathrm{g}}=$ $6.66 \times 10^{-2} \mathrm{~cm} / \mathrm{s}$, (c) ovalbumin, $\mathrm{pH} 4.6, u_{\mathrm{g}}=5.37 \times 10^{-2} \mathrm{~cm} / \mathrm{s}$, and (d) hemoglobin, $\mathrm{pH} 6.8, u_{\mathrm{g}}=5.37 \times 10^{-2} \mathrm{~cm} / \mathrm{s}$, respectively. 

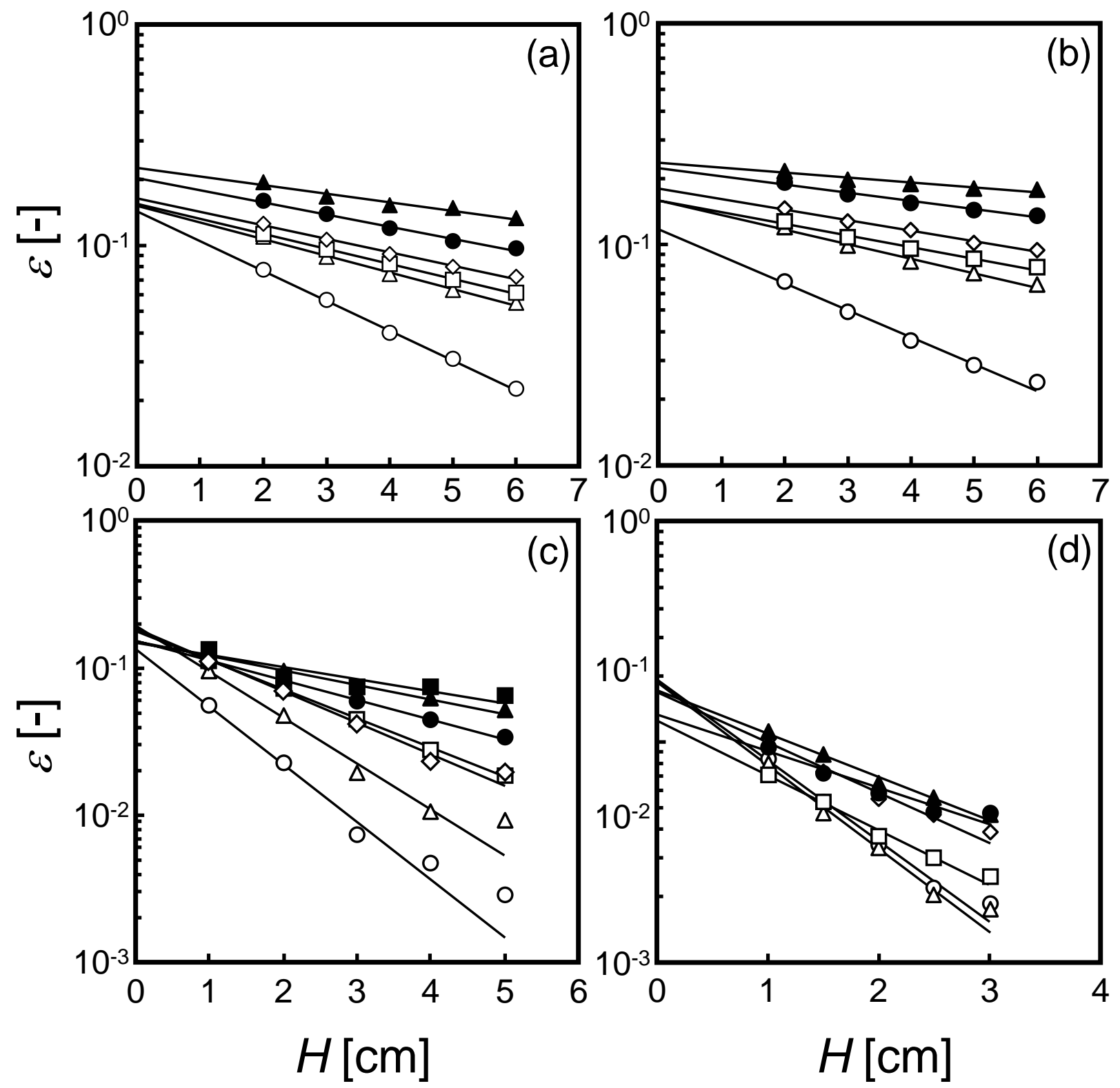

Fig. 2. Axial distribution of liquid holdup, $\varepsilon$, for SDBS ((a) and (b)), ovalbumin (c) and hemoglobin (d) in foam within continuous foam separation column. Symbols and experimental conditions are same as Fig. 1. Solid lines were calculated from Eq. (11). 

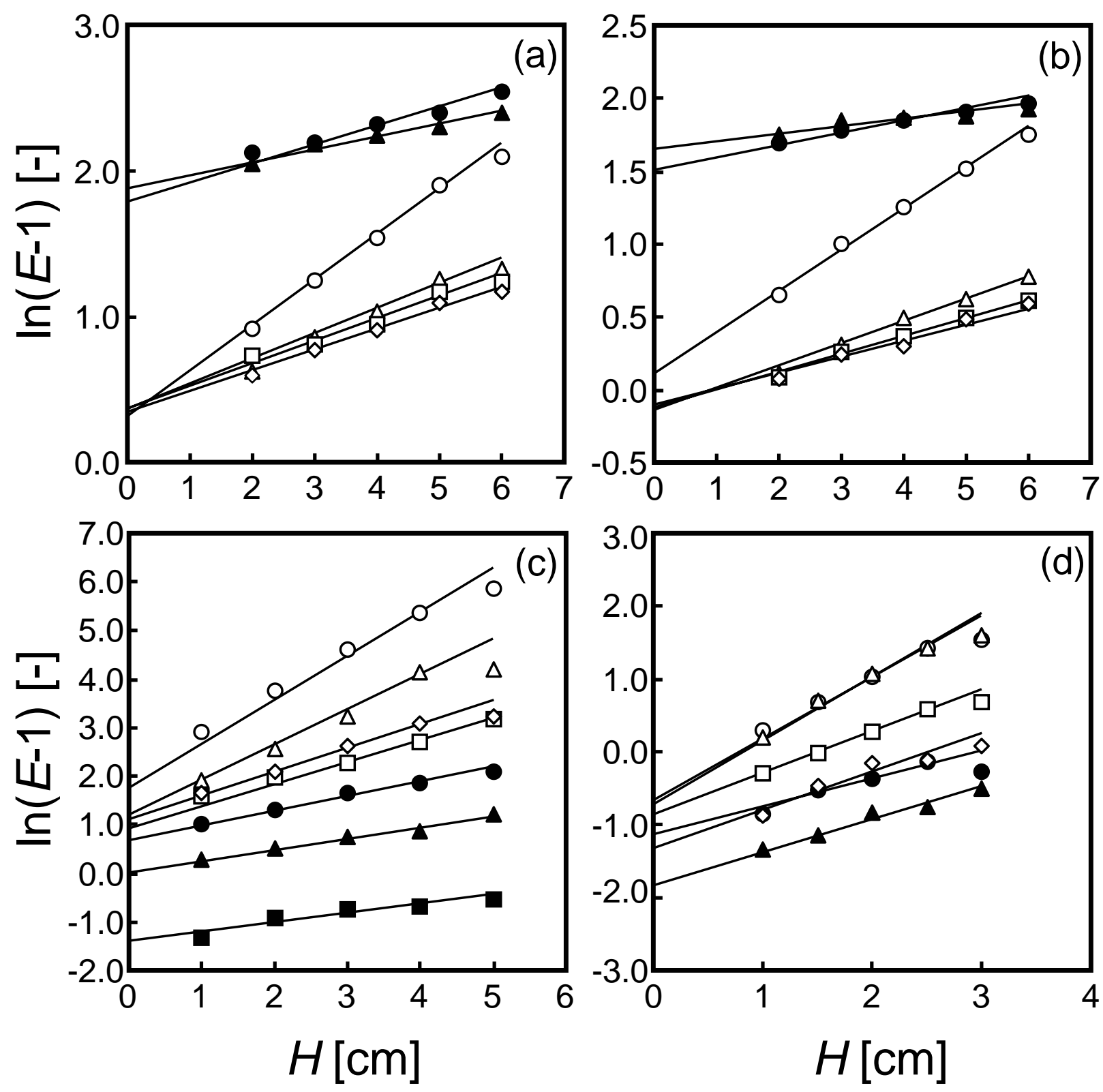

Fig. 3. Comparison of the experimental values of $\ln (E-1)$ and the calculated ones for SDBS ((a) and (b)), ovalbumin (c) and hemoglobin (d) in foam within continuous foam separation column. Symbols and experimental conditions are same as Fig. 1. Solid lines were the results of fitting of the data to Eq. (12). 

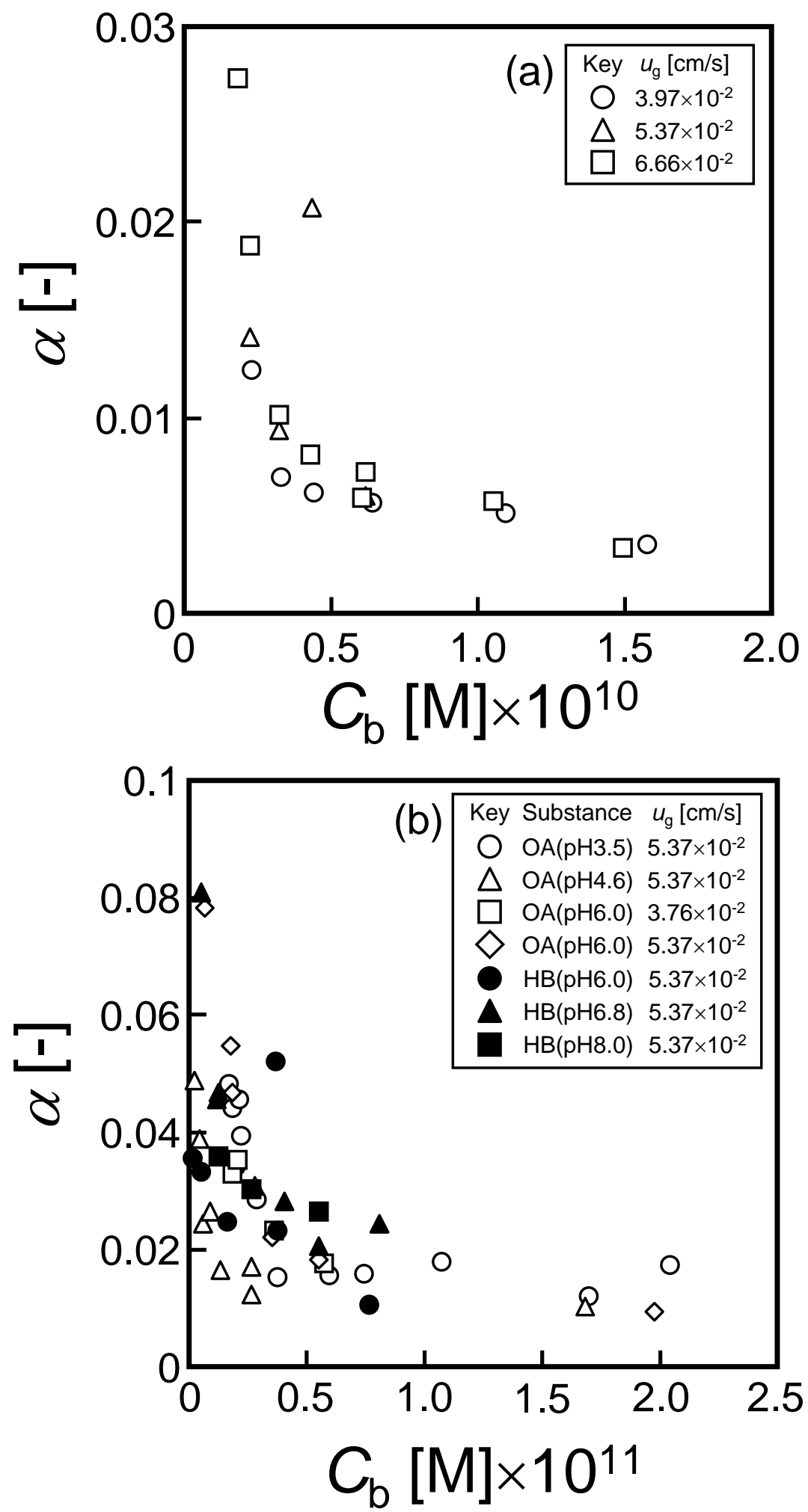

Fig. 4. Variation in $\alpha$ estimated from Eq. (11) for SDBS, ovalbumin (OA) and hemoglobin (HB). 


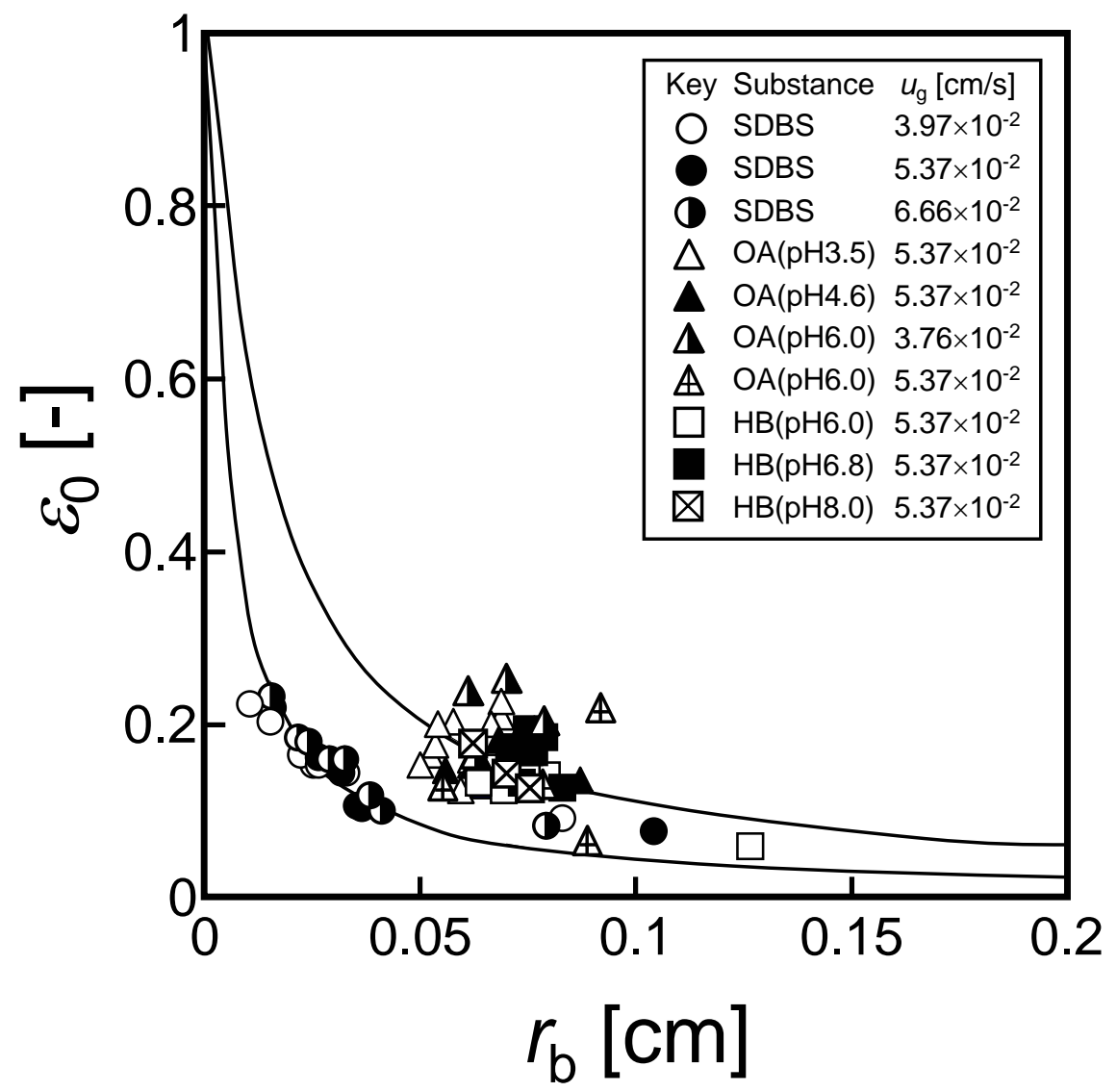

Fig. 5. Relationship between $\varepsilon_{0}$ estimated from Eq. (11) and bubble radius, $r_{\mathrm{b}}$, determined by Eq. (15) for SDBS, ovalbumin (OA) and hemoglobin (HB). 
Table 1. Adsorption Parameters for Proteins and SDBS

\begin{tabular}{cccc}
\hline & $\mathrm{pH}$ & $\gamma\left[\mathrm{kg} / \mathrm{m}^{2}\right]$ & $K\left[\mathrm{~m}^{3} / \mathrm{kg}\right]$ \\
\hline & 3.5 & $2.30 \times 10^{-6}$ & $3.94 \times 10^{2}$ \\
$\mathrm{OA}^{\mathrm{a}}$ & 4.6 & $3.39 \times 10^{-6}$ & $1.01 \times 10^{3}$ \\
& 6.0 & $1.92 \times 10^{-6}$ & $8.72 \times 10^{2}$ \\
\cline { 2 - 4 } & 6.0 & $1.96 \times 10^{-6}$ & $6.52 \times 10^{3}$ \\
$\mathrm{HB}^{\mathrm{a}}$ & 6.8 & $2.27 \times 10^{-6}$ & $5.88 \times 10^{2}$ \\
& 8.0 & $1.78 \times 10^{-6}$ & $1.27 \times 10^{3}$ \\
& & & \\
\multirow{2}{*}{ SDBS } & - & $1.22 \times 10^{-6}$ & $2.14 \times 10^{7}$ \\
\hline a Reference [22] & &
\end{tabular}

